\title{
Are Stories and Anecdotes an Underused Pedagogic Technique in Undergraduate Medicine? A Qualitative Study
}

Cara Richardson ( $\nabla$ cyrichardson@dundee.ac.uk)

University of Dundee

Linda Jones

University of Dundee

\section{Research Article}

Keywords: Storytelling, anecdotes, qualitative, student and faculty perspectives, pedagogic method, undergraduate medical teaching,

Posted Date: August 19th, 2021

DOl: https://doi.org/10.21203/rs.3.rs-796395/v1

License: (c) (i) This work is licensed under a Creative Commons Attribution 4.0 International License.

Read Full License 


\section{Abstract}

Background: Arguably storytelling is a recognised teaching method used in different fields such as teaching children, religion, and culture. Its use in medical teaching is apparent, but little is known of how valuable this method is within medical teaching. This study aimed to explore the perceptions stakeholders have of using stories within teaching and learning at Dundee Medical School. We hope to understand how stories are perceived and to consider how educators might optimise their use.

Methods: A qualitative approach allowed for the exploration of participants perceptions of storytelling within medical teaching. Purposive sampling was used to sample medical students and educators. Eleven students participated in one of three group semi-structured interviews and five individual semistructured interviews with educators took place. The data collected was coded and analysed to reveal themes and sub-themes regarding storytelling at Dundee Medical School.

Results: Both stakeholder groups sampled highly valued the use of stories and anecdotes within medical teaching. Whilst both suggested the same purposes, types and impact of stories and identified similar barriers to using storytelling such as confidence and experience. Students were more focused on the importance of the relevance, delivery, and context of where a story was being told for stories to be effective, whilst for faculty, their perceptions didn't involve these themes.

Conclusions: The findings from this small study have provided insight into how storytelling is perceived and developed some recommendations for optimising its use within medical education at Dundee Medical School. This highlights the value of this method to educators and exemplifies the important qualities stories can help to foster amongst students, whilst suggesting a possible theory on how to successfully utilise them.

\section{Background}

Storytelling has been a known pedagogy for many years and plays an integral part within the medical profession for instance, through hearing patients' stories, medical cases, errors, and triumphs $(1-3)$. It has been established as a successful tool to engage learners, encourage 'deep approaches to learning', reflection, and assist with knowledge recall $(4,5)$. Recent studies highlight the effectiveness of the teaching strategy within higher education to help students prepare for the challenges and uncertainties of working life $(6,7)$. Few studies have investigated the value and usage of storytelling within medical education despite its association with lifelong learning and promoting reflection in learners $(8,9)$. These are essential elements within current undergraduate medical curriculums (10).

Stories have been used to teach various healthcare professionals due to their positive impacts on learners. Multiple papers outline these impacts. Ogueh (11) found medical teaching involving emotive stories enhanced knowledge and helped develop feelings of empathy amongst students. Within a lecture setting, medical students are more likely to pay attention and to be engaged with course content when 
stories are used (12). Studies have also explored the impact stories have on the development of a professional healthcare identity $(13,14)$.

This small-scale study aimed to explore and understand stakeholder perceptions of the value of stories and anecdotes at Dundee Medical School (DMS). Investigating this, could enhance awareness of this method and reveal its significance and potential.

\section{Methods}

A qualitative research method, gathering data by semi-structured interviews then using thematic analysis was aligned to our aim of exploring stakeholders' perceptions. A constructivist approach sought not to generate one truth but to construct meaning and theorise and about the effective use and value of storytelling and anecdote.

\section{Participants}

Two groups of internal stakeholders: students and teaching faculty within DMS, the setting for the study were invited to participate by e-mail. Purposive sampling ensured a wide range of students and educators across different year groups and medical specialities were selected respectively.

\section{Data Collection}

Eleven students participated in one of three group semi-structured interviews and five individual semistructured interviews with educators were conducted and recorded all online within Microsoft Teams in early 2021. An interview guide was developed and piloted before data collection with stakeholders not involved in the study. Group interviews with students were used to generate richer data; focus groups were considered as an alternative but were discounted as they limit researcher interaction $(15,16)$. Individual interviews were the preferred method with faculty due to timetabling. Ethical approval was granted from the University of Dundee ethics committee.

Data collection was carried out by the primary researcher (CR), a medical student undertaking a BMSc in Medical Education. To mitigate potential researcher bias arising a research journal and field notes were kept during the data collection and analysis phase (17). These were discussed with the second author (LJ) during supervision.

\section{Data Analysis}

Consecutive interviews and analysis suggested theoretical saturation as according to Strauss and Corbin (18) had been achieved after the fifth faculty interview and third group interview as no new themes were emerging from the data. Recordings were transcribed verbatim and supplemented with field notes taken during data collection e.g., the addition of non-verbal cues. Thematic analysis by Braun and Clarke (19) was used to generate codes and transcripts were coded and hand searched for themes. Inductive reasoning methods were employed for the purpose of understanding and extracting themes from the 
data (20). Triangulation of data was used to compare and interpret the similarities and differences between data collected from students and educators.

\section{Results}

During data analysis, five themes emerged including 1. Purpose of stories 2. Emotive stories 3. Impact of stories 4. Effective use of stories 5 . Barriers to storytelling.

\section{Purpose of Stories}

The purpose and relevance of storytelling emerged as a key topic of discussion amongst stakeholders. Both groups of stakeholders $(n=10)$ agreed one of the main purposes of utilising stories was to give context to teaching and learning. Faculty also believed that using stories helped introduce students to the realities of medicine.

"(stories) can really humanise what you're trying to teach, rather than the kind of formulaic cases or theory, and it brings it to life...I think it really adds that human flavour of people's lived experience."

Faculty 2

Another purpose repeatedly mentioned by faculty was how storytelling helps engage students. Similarly, most students agreed that it makes them pay more attention in lectures, however, some expressed that engagement depends on the type of story being told.

\section{Emotive Stories}

In terms of types of stories, most of the definitions which emerged $(n=11)$ involved "real-life examples" (Student 6) or "previous experiences" (Faculty 5). Both stakeholder groups reported that current teaching most frequently utilised case-based stories. Shocking stories consistently emerged as being highly valued by students and educators also enjoyed delivering them.

"More of a shock factor at the end of it was the big reveal, this rare condition that nobody was thinking of. Then you can go away after thinking...I need to think of everything" Student 5

Several students revealed funny stories were effective, helped them build rapport with educators and encouraged them to listen. Funny stories were also liked by educators, but one expressed a potential drawback to utilising humour within teaching.

"There's a danger in laughing at your patients' expense...Storytelling to learn rather than storytelling for the purpose of gossiping." Faculty 2

\section{Impact of Stories}

Overall stories were highly valued and enjoyed by stakeholders' as they had a positive influence on teaching and learning. Students from all three group interviews $(n=9)$ commented that stories have 
helped progress their learning or knowledge recall. More students than educators believed that hearing stories gave them a sense of professional identity.

"take-home learning point at the end of it you're like aww I was not expecting that and...lodges in your brain a bit more." Student 4

"It's good it makes you imagine being there treating someone" Student 2

\section{Effective use of stories}

Students and some educators suggested the effectiveness of a story depended on the delivery, teaching environment and the reasons why it was told. Students liked stories to be relevant to the teaching and for them to be told interestingly or excitingly. Educators believed stories work best within interactive sessions where there is more time for discussion.

"you can make a really interesting case sound really boring if you don't know how to present it right. And the opposite is also true" Student 10

"Some tutorials... are an opportunity to speak about some of the information that's being presented in the lectures, and to ask questions I think you're more inclined to use stories or anecdotes, when it is less structured" Faculty 4

\section{Barrier to storytelling}

Staff and students both alluded to potential issues that may inhibit the value of storytelling in medical teaching. Some Educators $(n=2)$ and one group of students $(n=4)$ identified the importance of patient confidentiality when telling stories. Another barrier recognised by both stakeholder groups was the need to have clinical experience to tell stories within medical teaching.

"Careful about confidentiality...if it's such a unique case that it could be identified by someone then that's not going to be good" Faculty 2

"Less experience of teaching or you're less confident it's going to be harder, or you've got less clinical experience, then you're going to have less to draw on." Faculty 4

\section{Discussion}

\section{Why use stories?}

Using stories to give context and enhance students understanding of medicine was a purpose highlighted by both stakeholders and supports evidence from previous studies $(21,22)$. Students believed that when stories were used within lectures, they felt more involved in the teaching enabling them to pay more attention. Educators also noticed that students are more engaged when they employ this technique echoing research findings $(12,23)$. 
Storytelling allows educators to share with students some realities of medicine. Most research agrees with this purpose however, Greenhalgh in 2001 explained stories provide a poor account of medical conditions and traditional medical teaching and textbooks are superior $(24,25)$. These differences could be explained by stories representing how things happen in real life in comparison to textbooks. Perhaps now over twenty years on, students and educators prefer a variety and balance of both to properly prepare students for their careers. Could both pedagogic forms serve a purpose, and it is not one or the other but instead understanding when each method is most effective within teaching? Knowing this might help inform educators of when to deliberately employ these teaching methods.

Previous research reveals storytelling, as a tool helps students empathise $(11,26)$. Many student respondents concurred; however, no educators identified this benefit. Despite this understanding, are educators aware of storytelling's potential importance for successful medical student development?

Stories positively impacted students in this study. They reported learning about empathy, discovering the realities of medicine, being offered a context for learning, and feeling more engaged. The considerable alignment between the purposeful use of stories emerging from our student data with the evidence identified through our literature review could give confidence to educators using this method and encourage them to deliberately utilise it more.

\section{What types of stories should be used?}

Nearly every stakeholder thought of stories as re-telling past experiences to promote learning. Attenborough and Abbott (27) defined storytelling similarly. Students and faculty both suggested that case-based stories are told the most in medical teaching and are successful at promoting and enabling discussion between educators and students. This interaction can help educators explore for instance ethical issues and person-centred care (22). Other publications concur that case-based stories are highly valued, extensively used and can have a positive impact on student's clinical knowledge, and professional values $(23,28)$.

Students believed that shocking stories deepened their understanding of concepts and helped with information recall. Likewise, Clark (23) argued using shock or surprise within stories helped expand students clinical knowledge. We might infer that for students to find stories beneficial for learning they should involve some sort of emotive impact such as surprise, interest, or laughter.

Using humour also emerged from the data, as students felt it promoted more rapport and engagement with educators who utilised this teaching method. Its effectiveness in medical teaching has been previously recognised as it can create relaxed learning environments and makes teaching and learning enjoyable for both parties, when used appropriately $(29,30)$. The potential danger of mocking patients or doctors within a funny story was acknowledged by an educator and a similar problem has been highlighted by Piemonte (31) who explains it can damage students' professional values.

Several authors have written on the role of humour in health care for instance in palliative care $(32,33)$ and more explicitly in higher education $(34,35)$. Jones (4) helpfully adapted Dean and Gregory $(32)$ 
cautions and guidelines on the use of humour which is presented in Fig. 1.

Figure 1 Adapted from cautions and guidelines on the use of humour $(32,36)$

Caution 1 Never introduce yourself in a humorous manner unless your reputation has proceeded you.

Caution 2 Never use humour to conceal a lack of preparation or inadequate knowledge of the subject matter.

1. Make fun of yourself not others

2. laugh with people and not at them

3. Select material that relates to your topic or listeners

4. Believe in your material

5. Deliver your material well

6. Learn techniques for good delivery

7. Avoid ethnic/ sexist etc put-downs

8. Give listeners permission to laugh

9. Use savers if the joke or story doesn't work

10. Timing and intuition are important for choosing when and when not to utilise humour

Our study suggests some imbalance where surprising and humorous stories are the most valued by students, yet educators use case-based accounts the most. Our findings suggest that the deliberate type of story chosen, informed by an understanding of and reflection on the different benefits of each might be strategically valuable for all stakeholders.

\section{Value of Stories}

Both stakeholders highly valued and enjoyed storytelling. Students from this study and others highlight the popularity of this teaching method $(21,23)$. Students benefit from this enjoyment as they may be more likely to engage with teaching (37). The findings suggested that educators needed more clarity on students' attitudes towards stories being used within teaching. Perhaps this transparent account of the seeming value and purpose of stories might encourage more educators to deliberately use this method and help students to integrate ideas from stories and anecdotes into reflective activities.

Students believed stories also progressed learning by prompting recall, understanding context, advice for future career choices and engaging interest which literature suggests can deepen approaches to learning. $(4,21)$. These less direct purposes of storytelling were less evident in the data from faculty perhaps because they are delivering stories as opposed to experiencing them.

Storytelling is known to impact professional identity development (27). Although students didn't specifically acknowledge this, two groups of interviewees explained that hearing stories about good and bad clinical practice will help shape their future careers. Only one educator, acknowledged storytelling helping by involving students in the community of practice, developing a sense of belonging and 
encouraging them to progress, qualify and develop a sense of identity as a doctor. Belongingness in higher education can be defined as feeling accepted, appreciated and safe in the respected learning environment (38). This sense of belonging is highly valued for its positive impact on learner development, academic achievement and student wellbeing $(39,40)$. Through sharing medical stories can educators enhance belongingness amongst students and help them develop professional values?

In an earlier study, Jones (4) conceptualised the concept of a story as a learning platform. Figure 2 shows stories as learning platforms whereby sharing a story with learners served to convey concepts, ideas, and information. Analysis of data gathered using questionnaires and focus groups, populated by diverse educators she identified five potentials. Firstly, to encourage reflection on the shared experience, to engage learner interest, to create a positive learning environment, generation of eureka moments verisimilitude and finally the opportunity to generate discussion and debate on a topic.

We hope that disseminating these findings to educators could create a greater awareness of the value of stories and encourage educators to make more deliberate efforts to use them to their full potential.

\section{Safe \& Effective storytelling}

Both stakeholders expressed their fears that using stories could compromise patient confidentiality. This could be avoided through training or education ensuring patients or subjects aren't easily identifiable (perhaps by altering some non-essential details) when bringing life experience or stories into teaching (31). For example, a faculty development workshop, reflecting on participants' own experiences of storytelling could be created to help develop guidelines for safe and effective storytelling.

The delivery of stories was important to more students than educators. Students believed that for stories to be engaging and worthwhile they had to be told enthusiastically. Clark (23) also acknowledges the power educators have when choosing what stories to tell and how they are delivered.

It seemed for educators having the confidence and the experience to deliver stories influenced their use of this pedagogic tool. Students believed that having clinical experiences to draw on is essential for using stories within medical teaching. Interestingly, this reinforces that many participants thought of stories as real-life experiences and specifically only believed clinical stories are used or could be used within teaching. Stories have been used previously to deliver the less clinical aspects of medical teaching such as basic science but many participants overlooked this (21). Widening the perception of stakeholders' definitions of storytelling might be valuable for faculty development as not every story within medical teaching needs to be clinical or patient orientated. Consider perhaps whether using metaphors as stories, and hence learning platforms, might help educators convey basic science medical teaching and complex ideas and attitudes?

The literature surrounding storytelling in higher education generally suggests stories need to be relevant to teaching to benefit the learner (7). Similarly, this opinion emerged from students in this study. Does this mean stories should be constrained to those only with immediate relevance? Table 1 articulates the similarities between effective pedagogic intervention and storytelling which suggests this opinion may be 
unnecessarily constraining. Circulating this to stakeholders involved in teaching might be valuable to articulate the wider benefits of storytelling to enhance their deliberate use.

Addressing these conceptualisations as components of faculty development to promote safe and effective storytelling could guide educators on how to optimise choice and delivery of stories deliberately aligned to the desired learning processes or outcomes.

\section{Reflection}

Storytelling has been linked multiple times to successfully promoting reflection in learners, however, the term reflection didn't explicitly appear in our data $(22,43,44)$. Many of the themes already explored implicitly involve reflection and the interview itself involved participants reflecting on past experiences. Experiencing or delivering an emotive story can be thought of as a reflective process especially if it includes a "learning-point" that students can bring into future learning and practice (45). Perhaps neither stakeholder group acknowledging it illuminates how storytelling might facilitate an unconscious type of reflection. Moreover, storytelling could be part of the "hidden curriculum" within undergraduate medicine by promoting reflection, professional identity and the other purposes already described. Perhaps this too could be a focus for faculty development designed to articulate these benefits and enhance understandings of the implicit potentials of storytelling such as promoting reflective practice.

This discussion allowed the development of a possible theory for the successful utilisation of stories within medical teaching. This theory incorporates the study themes and is summarised in Figure 3.

\section{Strengths \& Limitations}

The strengths of this study include triangulation between the stakeholders and the primary researcher's (CR) insider perspective which has helped interpret and understand responses. She was assisted by LJ an experienced supervisor, who has undertaken previous research into storytelling for pedagogic purposes. We coded together during data analysis to enhance the trustworthiness of the inductive interpretation and mean-making. Whilst this study does not claim to be generalisable we hope its findings resonate sufficiently to increase discourses relating to the deliberate use of storytelling across other medical faculties.

The study also had some limitations. It had a relatively small size of sixteen, however theoretical saturation was still assumed to be achieved. Selection bias may have been introduced through disclosing the title and focus of the study during recruitment and attracting a sample who favour storytelling within teaching. Unfortunately, the research does not represent the entire medical school as no fifth-year students participated. However, it might be assumed that respondents' views on storytelling by year five are unlikely to change, as there weren't many differences in responses between the different year groups sampled.

\section{Conclusion}


The research aimed to explore the perceptions stakeholders at DMS had regarding storytelling as a pedagogic technique. The data suggested story and anecdote telling was viewed in a predominantly positive light. Generally, educators demonstrated limited insight into students' richer perceptions of storytelling for pedagogic purposes. Similarities between their perceptions included the purpose and types of stories used and the barriers to using this teaching method. One of the main differences was students' tendency to be very particular about where, how, and why a story would be used within the context of their learning to optimise effectiveness. Educators didn't tend to pick up on these delivery issues but rather focussed on a more limited set of purposes.

We hope our study has created a platform to inform faculty of the potential value of deliberately using storytelling as a method and how it could be used more broadly in the future. The findings enabled the development of a theory that involved combining the perceptions of both stakeholders and the positive outcomes of storytelling. Utilising this study to shape some faculty development activities might readily unleash some of the underused potentials for the deliberate use of this technique. Perhaps also enabling students to understand the wider values of stories for fostering lifelong learning and developing professional identities could also be considered for recognising and optimising learning opportunities offered by a wide range of well-chosen tales.

\section{Declarations}

\section{Ethics \& Consent}

Methods were performed in this this study in accordance with the declaration of Helsinki. Ethical approval was granted from the University of Dundee Schools of Medicine and Life Sciences Research Ethics Committee SMED REC Number 20/113. Informed consent was obtained from each participant making them aware of the purpose of the research, its voluntary nature, how their data will be recorded, used, and handled within the study.

\section{Consent for publication}

All the participants within this study have consented for publication.

\section{Availability of data and materials}

The data that support the findings of this study are available on request from the corresponding author $\mathrm{CR}$. The data is not publicly available due to containing information that could compromise research participant confidentiality.

\section{Competing interests}


The authors declare that they have no competing interests.

\section{Funding}

There was no funding for the study

\section{Authors' contributions}

CR under the supervision of LJ designed, analysed, and interpreted the data regarding storytelling medical teaching. CR was a major contributor in writing the manuscript. Both authors read and approved the final manuscript.

\section{Acknowledgements}

The authors would like to thank both student and faculty participants for their contributions, time, and enthusiasm for taking part in this research.

\section{Authors' information}

\section{Affiliations}

Centre for Medical Education, University of Dundee, Dundee, Scotland

Linda Jones

\section{Medical School, University of Dundee, Dundee, Scotland}

Cara Richardson

\section{References}

1. Deniston-Trochta GM. The Meaning of Storytelling as Pedagogy. Visual Arts Research. 2003;29(57):103-8.

2. Egnew TR. A Narrative Approach to Healing Chronic Illness. The Annals of Family Medicine. 2018;16(2):160-5.

3. Cooper K, Hatfield E, Yeomans J. Animated stories of medical error as a means of teaching undergraduates patient safety: an evaluation study. Perspect Med Educ. 2019;8(2):118-22.

4. Jones L. Metaphors, stories and humour as a learning platform. - Developing formative assessors with capabilities to encourage sustainable assessment. 2001. 
5. Barrett $\mathrm{H}$, editor Researching and evaluating digital storytelling as a deep learning tool. Society for information technology \& teacher education international conference; 2006: Association for the Advancement of Computing in Education (AACE).

6. Bruner JS. Making stories: Law, literature, life: Harvard University Press; 2003.

7. Clark MC, Rossiter M. Narrative learning in adulthood. New Directions for Adult and Continuing Education. 2008;2008(119):61-70.

8. Alterio $\mathrm{M}, \mathrm{McD}$ rury J. Learning through storytelling in higher education: Using reflection and experience to improve learning: Routledge; 2003.

9. McKillop C, editor Storytelling grows up: using storytelling as a reflective tool in higher education. Scottish Educational Research Association Conference, Perth, Scotland, 24-26 November; 2005.

10. General Medical Council. Outcomes for Graduates 2018: General Medical Council; 2018. Available from: https://www.gmc-uk.org/-/media/documents/dc11326-outcomes-for-graduates-2018_pdf75040796.pdf.

11. 11.

12. De Golia SG. How to Give a Lecture. Cham: Springer International Publishing; 2020. p. 65-81.

13. Haigh C, Hardy P. Tell me a story - a conceptual exploration of storytelling in healthcare education. Nurse education today. 2011;31(4):408-11.

14. Clark PG. Narrative in interprofessional education and practice: implications for professional identity, provider-patient communication and teamwork. Journal of interprofessional care. 2013;28(1):34-9.

15. Anne G. Mastering the Semi-Structured Interview and Beyond: From Research Design to Analysis and Publication. New York: NYU Press; 2012.

16. McLafferty I. Focus group interviews as a data collecting strategy. Journal of advanced nursing. 2004;48(2):187-94.

17. Berger R. Now I see it, now I don't: researcher's position and reflexivity in qualitative research. Qualitative Research. 2015;15(2):219-34.

18. Strauss AL, Corbin JM. Basics of qualitative research: techniques and procedures for developing grounded theory. 2nd ed. ed. Corbin JM, editor. Thousand Oaks, Calif: SAGE Publications; 1998.

19. Braun V, Clarke V. Using thematic analysis in psychology. Qualitative Research in Psychology. 2006;3(2):77-101.

20. Thorne S. Data analysis in qualitative research. Evidence-based nursing. 2000;3(3):68-70.

21. Easton G. How medical teachers use narratives in lectures: a qualitative study. BMC Medical Education. 2016;16(1):3.

22. Abildsnes E, Flottorp S, Stensland P. Case stories in general practice: A focus group study. BMJ open. 2012;2.

23. Clark PG. Values and voices in teaching gerontology and geriatrics: case studies as stories. The Gerontologist. 2002;42(3):297-303. 
24. Greenhalgh T. Storytelling should be targeted where it is known to have greatest added value. Medical education. 2001;35(9):818-9.

25. Hensel WA, Rasco TL. Storytelling as a method for teaching values and attitudes. Academic medicine. 1992;67(8):500-4.

26. Kumagai AK. A conceptual framework for the use of illness narratives in medical education. Academic medicine. 2008;83(7):653-8.

27. Attenborough $\mathrm{J}$, Abbott $\mathrm{S}$. Using storytelling in nurse education: The experiences and views of lecturers in a higher education institution in the United Kingdom. Nurse education in practice. 2020;44:102762-.

28. Cox K. Stories as case knowledge: case knowledge as stories. Medical education. 2001;35(9):862-6.

29. Ziegler JB. Humour in medical teaching. Medical Journal of Australia. 1999;171(11-12):579-80.

30. Liu Y-P, Sun L, Wu X-F, Yang Y, Zhang C-T, Zhou H-L, et al. Use of humour in medical education: a survey of students and teachers at a medical school in China. BMJ Open. 2017;7(11):018853.

31. Piemonte NM. Last Laughs: Gallows Humor and Medical Education. Journal of Medical Humanities. 2015;36(4):375-90.

32. Dean RA, Gregory DM. More than trivial: strategies for using humor in palliative care. Cancer Nurs. 2005;28(4):292-300.

33. Pinna MÁ C, Mahtani-Chugani V, Sánchez Correas M, Sanz Rubiales A. The Use of Humor in Palliative Care: A Systematic Literature Review. Am J Hosp Palliat Care. 2018;35(10):1342-54.

34. Evans TR, Johannes N, Winska J, Glinksa-Newes A, van Stekelenburg A, Nilsonne G, et al. Exploring the consistency and value of humour style profiles. Comprehensive Results in Social Psychology. 2020;4(1):1-24.

35. Baid H, Lambert N. Enjoyable learning: The role of humour, games, and fun activities in nursing and midwifery education. Nurse Education Today. 2010;30(6):548-52.

36. Garratt T. The Effective Delivery of Training Using NLP (Practical Trainer S.: Kogan Page Ltd; 1997.

37. Csikzentmihaly M. Flow: The psychology of optimal experience: Harper \& Row New York; 1990.

38. Levett-Jones T, Lathlean J. Belongingness: A prerequisite for nursing students' clinical learning. Nurse Education in Practice. 2008;8(2):103-11.

39. Vivekananda-Schmidt P, Sandars J. Belongingness and its implications for undergraduate health professions education: a scoping review. Education for Primary Care. 2018;29(5):268-75.

40. Qureshi A, Fino E, Vivekananda-Schmidt P, Sandars J. Validating an adapted questionnaire to measure belongingness of medical students in clinical settings. Cogent Medicine. 2019;6(1):1620087.

41. Miner A, Mallow J, Theeke L, Barnes E. Using Gagne's 9 Events of Instruction to Enhance Student Performance and Course Evaluations in Undergraduate Nursing Course. Nurse educator. 2015;40(3):152-4. 
42. Strauss S. The Passionate Fact: Storytelling in Natural History and Cultural Interpretation: North American Press; 1996.

43. Moon J, Fowler J. 'There is a story to be told... A framework for the conception of story in higher education and professional development. Nurse education today. 2008;28(2):232-9.

44. Hunter LP, Hunter LA. Storytelling as an Educational Strategy for Midwifery Students. Journal of midwifery \& women's health. 2006;51(4):273-8.

45. Boud D, Keogh R, Walker D. Reflection: turning experience into learning. London: Kogan Page; New York: Nichols Publishing Company; 1985.

\section{Tables}

Table 1 Jones (4) mapping between Gagne's pedagogic events and Strauss' purpose of storytelling (41, 42)

\begin{tabular}{|l|l|}
\hline Gagne's 9 Events of Instruction & $\begin{array}{l}\text { Purpose of Storytelling from "The } \\
\text { Passionate Fact" }\end{array}$ \\
\hline Activating motivation & Engaging the interest of listeners \\
\hline Informing the learner of the objective & Enabling visualisation \\
\hline Directing attention & Giving information \\
\hline Stimulating recall & Helping memory \\
\hline Providing learner guidance & Creating a relaxing environment \\
\hline Enhancing retention & $\begin{array}{l}\text { Questioning assumptions and } \\
\text { facilitating attitude change }\end{array}$ \\
\hline Promoting the transfer of learning & \\
\hline Eliciting performance & \\
\hline Providing feedback & \\
\hline
\end{tabular}

\section{Figures}


Figure 1 Adapted from cautions and guidelines on the use of humour $(32,36)$

Caution 1 Never introduce yourself in a humorous manner unless your reputation has proceeded you.

Caution 2 Never use humour to conceal a lack of preparation or inadequate knowledge of the subject matter.

1. Make fun of yourself not others

2. laugh with people and not at them

3. Select material that relates to your topic or listeners

4. Believe in your material

5. Deliver your material well

6. Learn techniques for good delivery

7. Avoid ethnic/ sexist etc put-downs

8. Give listeners permission to laugh

9. Use savers if the joke or story doesn't work

10.Timing and intuition are important for choosing when and when not to utilise humour

Figure 1

Adapted from cautions and guidelines on the use of humour $(32,36)$

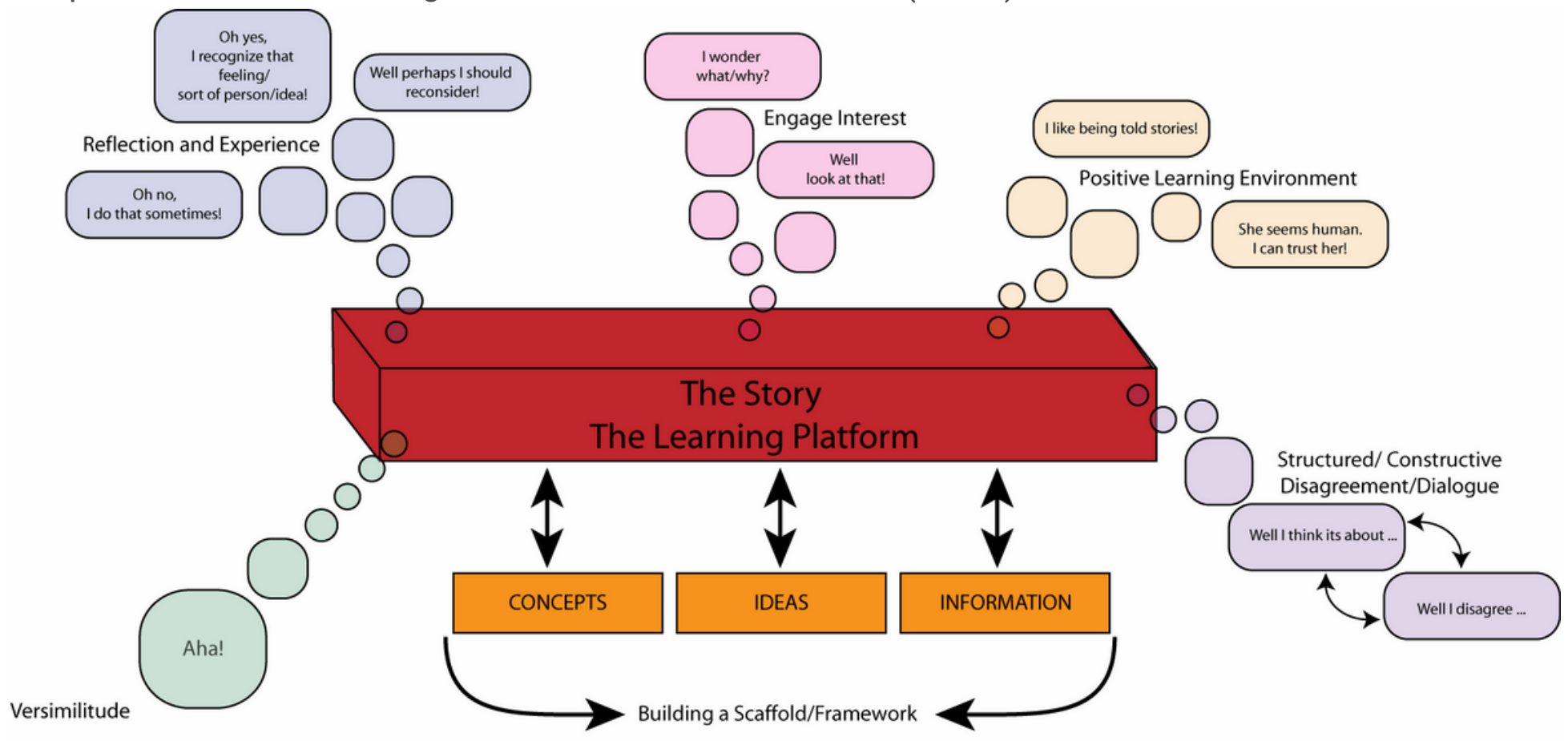

The Story As A Learning Platform

Figure 2 

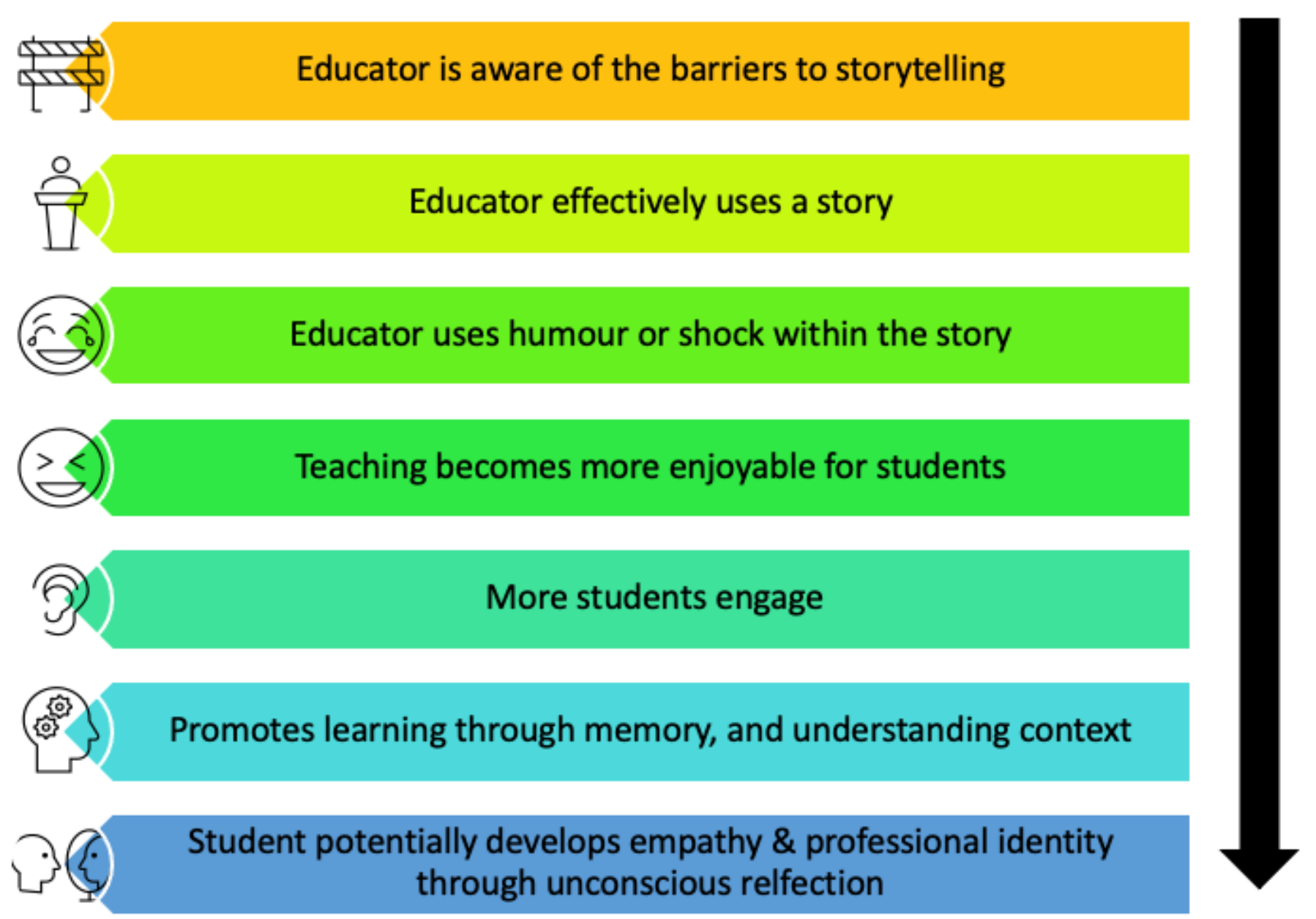

Figure 3

Possible Theory for Using Stories 